\title{
An Interview with P. K. N. Panicker
}

P. M. GIRISH

P. K. N. Panicker, (hereafter PKN) former President of the Indian Institute of Chemical Engineers, is a bilingual writer and has published four anthologies of poems. Other titles in English are Swami Vivekananda, Our Earth \& Our Environment. He has also published two anthologies of poems in Malayalam: Swapnangal, Athirukalkkappuram. His name is imprinted in the history of Indian translation since he has already translated the great works of Malayalam legendary poets like A. Ayyappan, Vailoppilli Sreedhara Menon, P. Kunhiraman Nair, Akkitham, and Vishnu Narayanan Namboodiri into English.

P. M. Girish (hereafter PMG) is an Associate Professor \& H.O.D, Department of Malayalam, University of Madras, Chennai, where he teaches since 2004. His primary areas of research are Socio-linguistics, Critical Discourse Analysis, Cognitive linguistics, translation studies, and literary criticism. He writes both in Malayalam and in English. Among the many awards, he has received are Kerala Sahitya Akademi I. C. Chacko Endowment and the Best Researcher Award (University of Madras).

PMG: You are a chemical engineer. How did your interest in literature begin?

PKN: My father was a teacher of literature (Malayalam) and from the very young days' father instilled the habit of extensive reading - of literature, both Malayalam and English. Almost by the age of ten, reading became a passion - reading everything that came to my notice and which I could access. Social themes, History of Literature and Political Philosophy became more and more absorbing and an urge to contribute my thoughts. By 14, I started writing articles in minor Malayalam 
weeklies. After 18, the focus shifted to Engineering subjects and English literature.

PMG: Your literary life started with writing poems both in Malayalam and in English. How did you decide to become a full-time translator?

PKN: It is not correct to say that my literary life started with writing poems. In fact, poems came much later. I graduated in Engineering in 1958 and from 1963 onwards, I started publishing technical articles (Science literature) in many Chemical Engineering Journals in India. I was also interested in Popular Science. The first book I published in 1981 titled 'Alcohol' in Malayalam is a highly technical one, detailing the design of an Alcohol Distillery. That was followed by a collection of Popular Science articles on various metals under the title, 'Lohangalude Lokam' (Malayalam); that was at a time when Popular Science had not found its feet not only in Malayalam but also in all Indian Languages - and perhaps even today. I also tried my hand on One Act Plays and a collection titled 'Palamukhangal' (Malayalam) was published in 1986. However, I did not seriously concentrate on that area either - same was the case with Short Stories. Though 5 or 6 of my stories were published by Malayalam monthlies from Bombay and Chennai. I did not pursue my effort in that direction. I started writing poems much later - to be precise, in 2004 only, when I was 68 - that too starting with English Poems.

As for translations, my entry was into translations of folktales. During one of my visits in 2002 to USA, I had the occasion to go often to a Children's Library in Corvallis along with my granddaughter. I was astonished at the enormous collection of books - folktales from different Parts of the World collected and translated into English. In the evenings, I used to read out the stories to her. While doing so the thought occurred, why 
not translate some of them into Malayalam - though not from the original, using English as the interlocutory medium, for the benefit of our children. Since then, I have published 130 stories, in 12 volumes, each with the introductory exposure to the geography, history and culture of the land from where the story is; from Asia, America, Africa, China, Japan, Ireland, Germany, etc. The first Volume was published by Mathrubhumi Books in 2004. I continue my effort in this direction.

As far as the translation of Malayalam Poems into English is concerned, a major activity that I presently concentrate on started quite unexpectedly. While sharing the dais on the prestigious Asan Award presentation function to A. Ayyappan, sadly converted into an occasion to condole, on 23 October 2010 that the thought occurred to me, "Why not try to translate A. Ayyappan into English and take him closer to the internationally acclaimed names in the world of poetry?' Moreover, my effort in that direction continues - taking Malayalam poets closer to the internationally acclaimed names in the world of poetry.

PMG: Selection of the work for translation is very significant. What are the criteria for selecting works for translation? The selection itself makes a judgment that creates power. What do you think?

PKN: Selection of work for translation, unless dictated by circumstances, is a complex task and equally significant. In my case, it was a combination of both - circumstance and personal choice. I have already explained the circumstance that made me take up the translation of poems seriously - and obviously, A. Ayyappan was the first choice. After that, since my objective was to take Malayalam poets closer to the internationally acclaimed names in the world of poetry, I looked at the most prominent and acclaimed Malayalam poets 


\section{P. M. Girish}

during the second half of the century that preceded - obviously the first names that came to me were Vailoppilli Sreedhara Menon, P. Kunhiraman Nair, and Akkiham Acuthan Namboothiri. Thereafter, when it came to the selection of the poems to be included in each of the compilations, personal likes and dislikes, affinity to the message carried by the poem and to what extent the message was in line with my own thoughts, and the ingrained message that I wanted to transport from this country to the readers placed in other spaces, etc. played a significant part. In this context, I agree with the observation that, 'The selection itself makes a judgment that creates power'.

However, the other equally important factors in the selection process are: Translator's liking, the content as he understands it in-depth and after unraveling the metaphorical expressions and statements, an identity with the message carried if any and a comfort level with the syntax and vibe of the poem in its totality.

PMG: How did you approach A. Ayyappan who used exemplary meta-language in his writing?

PKN: Yes, Ayyappan's words indeed carry much more than the meanings of the words; though it is true generally with poetry, most poets achieve their objective with the help of metaphors, similes, or allegories whereas Ayyappan achieves it through a syntactic structure placing his words in his own special way. From this point of view, Ayyappan's poems are often difficult to translate.

I tried to choose poems that were less complex from this angle (poems that leaned more on metaphors than on meta-structure) and also tried to lean more towards the meaning that words carried than on unraveling the hidden imageries - to this extent the translation is indeed weak. Even so, many of his poems have a universal appeal easily assimilated by others as well. 
People

trampling over the blood

of the one who died

in the road accident;

my eyes on the five Rupee Note

slipped out from his pocket.

(Dinner - Selected Poems of A. Ayyappan)

When studying history

some people

underline specific lines.

Missed past

is the book of history.

Every line of that book

deserves to be underlined.

All paths

moves along defined lines.

(Underline - Selected Poems of A. Ayyappan)

PMG: Your approach to the translation of Vailoppilli Sreedharan Menon differs from A. Ayyppan. Could you share your experience?

PKN: Yes, quite naturally as the two poets as individuals and their approaches to poetry vastly differ. Vailoppilli represents a period of transition of Malayalam poetry from romanticism to realism and surrealism; the question of how to write, yielding space to what to write? Consequently, Vailoppilli's poems present a blend of delicate human sentiments and romantic imageries easily understood and digested by his readers and likewise the translator too. As a translator, I found working with Vailoppilli's poem easier and equally enjoyable.

PMG: P. Kunhiraman Nair (also known as ' $P$ ') is well known for his symbolic writing. He uses rituals, myths, and romantic nature in his poems. Did you face any intricacy while translating them? 
PKN: In translating ' $\mathrm{P}$ ' there were a few problems - the toughest to deal with was the fact that his space (nature) is exclusively Keralite, rooted and nurtured in the beaches, hills, valleys, and villages of Kerala; myths and fables sprouted in the hearts of the ancients in Kerala; space stuck in every nook and corner with Keralite identities symbolizing its cultural ethos - it is indeed difficult to transport and transplant a space of that nature in another circumstance and space. Perhaps that was what made a distinguished scholar Sukumar Azhikode say, 'Here is a poet who cannot be translated'; and made me write that the translated poems of ' $\mathrm{P}$ ' are in the hands of the readers to measure the extent of my failure.

New science happily received the dawn of the progressive reformation of men's minds in the civilized era; voices of the inner souls reverberated.

(God of the Poor - Selected Poems of Mahakavi P Kunhiraman Nair)

In this context, I may add that translating Akkitham was also tough for the reason that each of his poems, as he himself described, 'the physical and the metaphysical exist in a beautifully meshed co-existential state' camouflaged in allegories picked up from the mythology steeped deep in the customs and rituals of Kerala - the transportation of which to another language and culture is a daunting task.

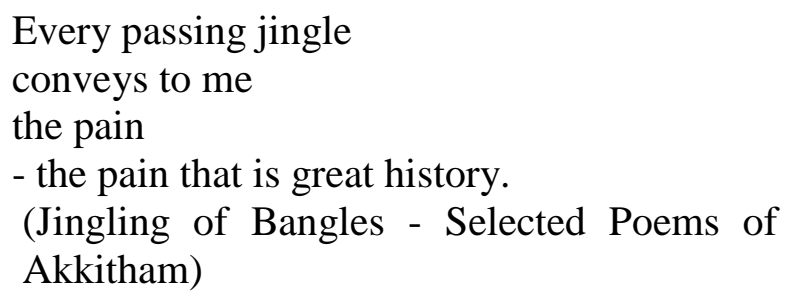

PMG: Could you share your experience of translating Vishnu Narayanan Namboodiri? 
PKN: Vishnu is rooted more firmly in contemporary space even as he is an admirer of the past and acknowledges his indebtedness to the ancient civilization of India that nurtured him. May be, because his thoughts and his style of expression were closure to my liking. Earlier I found translating Vishnu easier than others. I enjoyed translating his works - and many of them are direct, unambiguous political statements.

PMG: Other than poetry, did you translate anything from Malayalam to other languages?

PKN: Really not, except perhaps one short story - recently and posted in an online journal.

PMG: The literary genre like short stories and novels are very rich in Malayalam. Do you have any plan to translate some of them into English?

PKN: No. Not at present; but may be if time permits (I am 83). I sincerely wish that the next generation might take up the translation of science fiction and popular science into Malayalam seriously and more extensively.

PMG: As you mentioned earlier, you have also translated science writing into Malayalam. How does the art of translating science differ from translating creative writing?

PKN: Translating science is more exacting - needs in-depth knowledge of the subject as much or more than the original writer; equally thorough knowledge of both source and target language, familiarity with science terminology, words, and expressions; very correct and comprehensive understanding of the meaning of each word used. In fact, science translation, though may not be a creative one, is more demanding and strenuous. On the other hand, the translation of popular science is easier and enjoyable. 
PMG: Translation is a reciprocal and creative communication between the source language and the target language. As a committed translator, do you agree with this?

PKN: The translator is primarily a 'message conveyor'. However, this understanding becomes highly inadequate when dealing with the translation of creative literature and especially so with poetry. Translators of poetry necessarily engage in a process of negotiation between two cultures, two languages, and two different mindsets. A process that calls forth a profound understanding of the language they are translating from and a fluency in the language they are translating into. The complex and creative process of adapting one text into a new reality, mediating between the source and target languages makes the translator's task not only intricate and demanding but also highly creative. In the process of adaptation, the techniques used thereat have to vary from context to context making the creativity of the translator highly relevant.

PMG: Translation is never a total reflection of the original. Comment with your experience.

PKN: Translation per se is an act of conveying a message and this is true in matters concerning documentation where creativity is totally absent. However, translations of no creative work can never be a total reflection of the original; the extent of deviation from the original will depend on the depth of the creative element in the original work and the ability of the translator to suppress his creative urge when engaged in translation. Even so, a translator is always tempted to instill something personal in their work and translators approach a text in a different way. If a text were given to more than one translator, then we would witness more than one translated version. Creativity is inherently personal and hence every translator will have a personal translation style manifesting his or her creative approach. 
PMG: The translation is a political act since it creates power and dominance over the target language. Do you agree with this?

PKN: That depends on our understanding of what a political process really is. In a sense, every human endeavor has a political element. Translation too perhaps is no exception. It is through translation that political concepts emerging in one cultural environment are transported across linguistic boundaries, to other spaces and impact intellectual and social debates in new contexts. Intergovernmental diplomacy has often been conducted through translation, and social and international conflicts are often mediated, assuaged, or exacerbated through translation. Translation remains the main vehicle through which globalization processes are enabled; it operates at the interstices of military, economic and cultural power. Translation also plays an instrumental role in news media, and hence in circulating or resisting alternative narratives and ideologies. Even though we do not always think of translation as a form of political advocacy per se, nor should we, it goes without saying that literary translation can be a deeply politically biased act, making selected texts accessible to readers by transporting them across linguistic boundaries, making them think differently than otherwise.

To quote a few examples from my own translations:

Akkitham's 'Epic of the Twentieth Century' (Selected Poems of Akkitham) is an unmistakably transparent political statement wherein he exposes the distortion in the social positioning by different groups (and political parties), cliques, and individuals. Likewise, Vishnunarayanan's 'Globalisation, An Ancestral Family Legend and In Front of The Monument of Karl Marx' (Selected Poems of Vishnunarayanan Namboodiri) are unambiguous political statements. Can 
anyone deny that Vailoppilli's 'Kudiyozikkal' is a powerful socio-political statement?

Oh! The learned,

custodians of enlightened world culture,

this new epoch in history

offers you a challenge!

Can you eradicate

the moribund social order

of ubiquitous inequalities

walking on the path

of love beautiful, enchanting?

Be quick, quick,

no time to waste!

(Selected Poems of Vailoppilli Sreedhara Menon)

You the sage-like great one realized this truth on some auspicious enlightened moment.

You exposed threadbare the great drama

being played between the two classes

- the haves and the have-nots;

But how is it that missed the other class

- the unwanted?

'(In Front of the Monument of Karl Marx'Selected Poems of Vishnunarayanan

Namboodiri)

PMG: You have been living in Chennai for decades and you are familiar with Tamil Culture and Language. Did you translate anything from Malayalam into Tamil or Tamil into Malayalam?

PKN: No. Not much to mention - just three or four poems.

PMG: What is your future plan in the field of Translation? 
PKN: I hope to publish 'Selected Poems of Sugathakumari, the well-known poet and environmentalist, the manuscript is almost ready, waiting for some formalities. I propose to pick up one or two contemporary, younger generation poets - and I am working on a collection of poems by Malayalam poets living in Chennai.

PMG: How did the readers and critics approach your translation so far?

PKN: The comments were generally very encouraging both from the academicians and from readers.

***

\section{Cite This Work:}

GIRISH, P. M. 2021. An Interview with P. K. N. Panicker. Translation Today, Vol. 15(1). 235-245.

DOI:10.46623/tt/2021.15.1.in2 